\title{
Quantitative Morphological Evidence for Incipient Species within Lutzomyia quinquefer (Diptera: Psychodidae)
}

\author{
JP Dujardin/+, F Le Pont*, E Martinez*
}

Unité Mixte de Recherche IRD-CNRS 9926, Montpellier, Av. Agropolis 911, Montpellier, France *IRD La Paz, Casilla Postal 9214, La Paz, Bolivia

\begin{abstract}
Morphological variation among geographic populations of the New World sand fly Lutzomyia quinquefer (Diptera, Phlebotominae) was analyzed and patterns detected that are probably associated with species emergence. This was achieved by examining the relationships of size and shape components of morphological attributes, and their correlation with geographic parameters. Quantitative and qualitative morphological characters are described, showing in both sexes differences among local populations from four Departments of Bolivia. Four arguments are then developed to reject the hypothesis of environment as the unique source of morphological variation: (1) the persistence of differences after removing the allometric consequences of size variation, (2) the association of local metric properties with meristic and qualitative attributes, rather than with altitude, (3) the positive and significant correlation between metric and geographic distances, and (4) the absence of a significant correlation between altitude and general-size of the insects.
\end{abstract}

Key words: Lutzomyia quinquefer - geographic variation - speciation - morphometrics

Lutzomyia quinquefer (Dyar 1929) belongs to the medically important genus Lutzomyia Franca, 1924 of Phlebotominae (Diptera, Psychodidae). It was originally described from Iguazu falls (Missiones, Argentina, Dyar 1929) and has been reported from east Brazil, north Argentina, Paraguay and Bolivia (Young \& Duncan 1994). Previously forming part of the Helcocyrtomyia subgenus, series peruensis (Martins et al. 1978), L. quinquefer is now classified as a member of the oswaldoi species group, which contains no species of medical importance (Young \& Duncan 1994). These last authors described in males of $L$. quinquefer 5 setae on the coxite (fig. 280, G, page 691), while 12 were reported in the original description (Dyar 1929). In Bolivia, we found stable differences in this character between five geographic populations: 11 to 13 setae, as described by Dyar (1929), in the lowlands of the Department of Santa Cruz (Païlon, $200 \mathrm{~m}$ a.s.l.), 5 to 6 setae as described by Young and Duncan (1994) in Beni (Rurrenabaque $450 \mathrm{~m}$ a.s.l.), two localities of the Department of La

This work was supported by IRD (French Institut de Recherche pour le Développement) and the French Ministry of Foreign Affairs.

${ }^{+}$Corresponding author. Fax: +591-2-243782. E-mail: dujardin@mail.megalink.com

Received 29 January 1999

Accepted 11 August 1999
Paz: Cerro Pelado (Alto Beni, $900 \mathrm{~m}$ a.s.l.) and Pararani (Yungas, $1560 \mathrm{~m}$ a.s.l.), and 1 seta in the southern Department of Tarija (Huacalque, $1100 \mathrm{~m}$ a.s.l.). Linked to these variations, other quantitative and qualitative differences could suggest the occurrence of "incipient species" within $L$. quinquefer.

\section{MATERIALS AND METHODS}

Insects - A total of 106 specimens of $L$. quinquefer (69 males and 37 females) was submitted to morphometric analysis. All specimens were mounted in the same medium (Euparal) and measured by the same investigator (FLP). Metric properties of males were compared among five localities (Fig. 1): Païlon (6 individuals, group "MP”, Department of Santa Cruz), Rurrenabaque (20 individuals, group "MR", Department of Beni), Cerro Pelado (10 individuals, group "MC", Alto Beni, Department of La Paz), Pararani (10 individuals, group "MY", Yungas, Department of La Paz) and Huacalque (23 individuals, group " $\mathrm{H}$ ", Department of Tarija, bordering Argentina). Females of $L$. quinquefer were compared among the same localities, excluding Cerro Pelado: Païlon (7 individuals, group "FP"), Rurrénabaque (9 individuals, group "FR"), Pararani (10 individuals, group "FY") and Huacalque (11 individuals, group "FH"). Thus, both sexes came from four Departments of Bolivia: Santa Cruz (MP, FP), Beni (MR, FR), La Paz (MY, MC and $\mathrm{FY}$ ) and Tarija (MH, FH).

Morphological examination - Diagnosis of $L$. quinquefer followed the key of Young and Duncan 
(1994): all the male specimens presented small eyes, a similar shape of paramere (Dyar 1929) and a coxite basal tuft of semi-foliaceous setae. Length and form of setae are described. Female specimens presented the same general strong infuscation as in males, including pleurae, and shared very similar cibarial armature and spermathecae. Features related to denticulation patterns of apex of laciniae (part of maxillae) were examined in each group.

Morphometrics - Using a camara lucida, we measured the following features of the head: AIII third antennal segment, EP - labrum-epipharynx, P5 - fifth palpomere; of the wing: AL - alpha, BE beta, GA - gamma, WW - wing width, WL - wing length; and of the genitalia: GF - genital filaments, GP - genital pump, LL - lateral lobe. The mean length of coxite setae (setae of the coxite tuft) was estimated in males on a minimum of ten setae.

Numerical analyses - Metric properties, i.e. mean and standard deviation as well as minimum and maximum values, were computed for the 11 variables in each group. The same calculations are shown for the setae on coxite (male specimens).

In order to be consistent with small samples in some groups, a subset of four size-related measures (see below: AIII, EP, WW, WL) was used in multivariate analyses of each sex, with the length of LL as an additional measure in males.

The log-transformed measurements (Pimentel 1992) of these five measures were used for principal component analysis (PCA) and for canonical variate analysis (CVA). Tests for homogeneity of individual variance matrices showed no strong departures from homoscedasticity $(\mathrm{P}=0.0683$ in females; $\mathrm{P}=0.0243$ in males), so that the pooled within group matrix of variances was used. The first pooled within-groups principal component (PC1) generally reflects size differences between individuals (Bookstein 1989, Dos Reis et al. 1990). This was verified by the positive and significant correlation of each variable with PC1 (Dos Reis et al. 1990), so that size variation of specimens could be illustrated by quantile plots along the PC1.

We carried out Burnaby's (1966) method for allometric size correction, and performed two different CVAs: one including size variation, performed on the log-transformed data (SICVA, for "size-in" CVA), the other excluding allometric trends, performed on the variables projected onto the orthogonal space to PC1 (Burnaby 1966) (SFCVA, for "sizefree" CVA). Discrimination was performed either on five groups according to locality (MH, MY, MR, $\mathrm{MC}$ and MP), or on four groups according to the Department of origin: Santa Cruz (MP, $n=6$ ), Beni (MR, $\mathrm{n}=21$ ), La Paz (using MC and MY as one group, $\mathrm{n}=20)$ and Tarija $(\mathrm{MH}, \mathrm{n}=23)$. A similar sample processing was done in females, represent- ing either four groups: Santa Cruz (FP, $\mathrm{n}=7)$, Beni $(\mathrm{FR}, \mathrm{n}=9), \mathrm{La} \mathrm{Paz}(\mathrm{FY}, \mathrm{n}=10)$ and Tarija $(\mathrm{FH}, \mathrm{n}=11)$.

Results were illustrated by scatters of specimens along the first two canonical factors, with polygons enclosing each locality. Statistical significance of multivariate analyses was estimated by the Wilks statistics (Wilks 1932). The corresponding discriminant classifications were summarized, and verified statistically by using the Kappa statistics (Landis \& Koch 1977).

In males, we explored the correlation between geographic and multivariate distances between samples by means of the Mantel test (Sokal \& Rohlf 1995). Mahalanobis distance was used because it takes into account correlations between variables (Mahalanobis 1936). We also examined the correlation level (F-statistics) between altitude and differences in relative size (as estimated by PC1) and form (as estimated by first canonical factor of SFCVA).

Calculations used the NTSYS 2.02i (Applied Biostatistics Inc., Rohlf 1986-1998), the JMP (SAS Institute 1995) and the STATA (Computing Resource Center 1992) packages.

\section{RESULTS}

Collection sites - Insects were collected in areas presenting striking differences in altitudes (from 200 to $1560 \mathrm{~m}$ a.s.l.) and at distant localities (Fig. 1).

Univariate analysis - Mean, standard deviation, minimum and maximum values of measurements are presented for each character in Table I. Length of setae were significantly different among departments $(\mathrm{P}=0.0125$ after non parametric analysis of variance). The detailed statistical, univariate comparisons of other characters among groups is not reported.

Multivariate analysis - The first pooled withingroup PC1 represented $46 \%$ of the total variation in females, $62 \%$ in males, and showed significant and positive correlations with each variable in both sexes $(\mathrm{P}<0.0001$ after Bonferroni test, detailed results not shown). As a general-size variable, it showed (Fig. 2) that group MH (1 seta) was composed of the largest male specimens, followed by specimens of groups MC (5 setae), MY (5 setae), MR (5 setae) and MP (12 setae) (Fig. 2, bottom). A similar pattern was observed in females (Fig. 2, top).

In males, both size-in and size-free CVAs (Fig. 3) paralleled the PCA, distinguishing Paillon (MP with 11-13 setae on coxite, corresponding to the original description of Dyar 1929) and Huacalque (MH, 1 seta) from the remaining, overlapping localities (MY, MR, MC). This pattern was also apparent in females after size-free CVA (Fig. 4). However, the samples from Yungas (FY, $1560 \mathrm{~m}$ ) and Huacalque (FH, 1100 $\mathrm{m})$ overlapped in females (Fig. 4).

Observed classification scores were high what- 


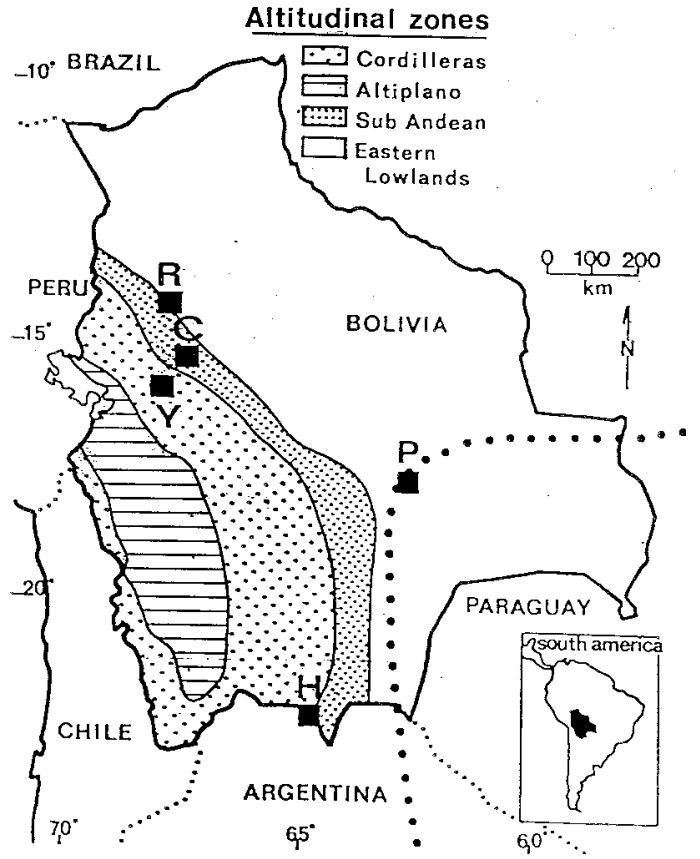

Fig. 1: map of Bolivia showing the geographic location of each morphotype of Lutzomyia quinquefer in relation with physiographic zones. Black squares indicate the locality of collections: R (Rurrenabaque, Department of Beni - 450 $\mathrm{m}$ a.s.l.) and P (Pailon, Department of Santa Cruz - $200 \mathrm{~m}$ a.s.1.), both localities in the lowlands of Bolivia; Y (Pararani, Yungas, Department of La Paz - $1560 \mathrm{~m}$ a.s.1.) and $\mathrm{H}$ (Huacalque, Department of Tarija - $1100 \mathrm{~m}$ a.s.1.), two localities of the Cordilleras; and C (Cerro Pelado, Alto Beni, Department of La Paz - 900 m a.s.1.) located in the Sub Andean area of Bolivia. Dashed line delimits the known eastern territory of L. quinquefer (Dyar, 1929).

ever the kind of CVA (from 77 to $94 \%$ in males, 77 to $90 \%$ in females), always significantly higher than expected by chance (from 22 to $43 \%$ ), and were generally improved when considering FY and FR (females) or MY, MC and MR (males) as one group (Table II).

Size, form and geographic distances - The significance level of correlation between Mahalanobis and geographic distances was possible to compute for males only ( 5 groups, 120 permutation) (see Sokal \& Rohlf 1995, p. 813-819), showing significance whether the Mahalanobis distances were computed from size-in (SICVA, $\mathrm{P}=2 / 120$ ) or sizefree variables (SFCVA, $\mathrm{P}=5 / 120$ ).

Size, form and altitude - In both sexes the populations at highest altitude (Yungas, $1560 \mathrm{~m}$ ) did not exhibit the largest sizes, which were found in Huacalque (1100 m) (Fig. 2). Accordingly, there was no detectable significant correlation between size (PC1 mean values) and altitude either in the total

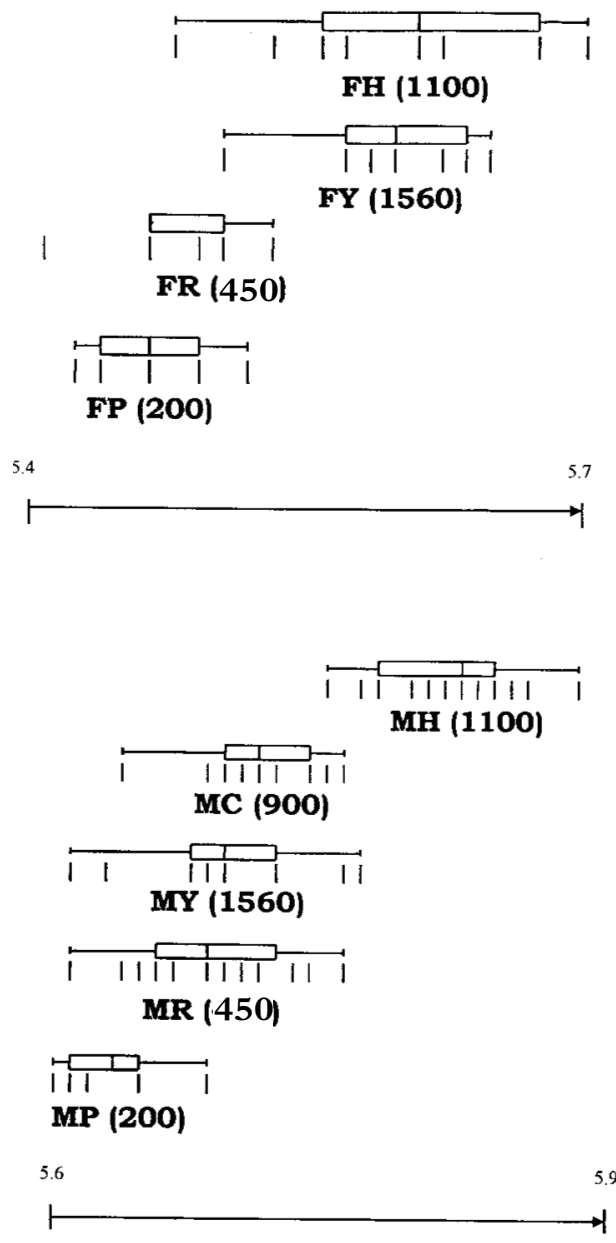

Fig. 2: quantile plots showing in each sex the distribution of individuals of different groups of Lutzomyia quinquefer along the first within-group principal components (PC1). Each box shows the group median separating the 25 th and 75th quartiles, with the 10th and 90th quartiles shown as lines on the right and left sides of the box. M: males; F: females; H: Huacalque, Tarija (males with 1 seta on coxite); P: Pailon, Santa Cruz (males with 11-13 setae); Y: Pararani (Yungas) C: Cerro Pelado (Alto Beni); and R: Rurrenabaque (Beni), all males with 5-6 setae on coxite. Altitudes (meters) are indicated between brackets.

sample (males and females, $\mathrm{P}=0.08$ ) or in each sex separately (males, $\mathrm{P}=0.48$ and females, $\mathrm{P}=0.10$ ). Form differences, estimated by the first canonical factor values on form variables (SFCVA), were also uncorrelated with altitude (detailed results not shown).

Morphological examination - In both sexes, careful morphological examination revealed some distinctive features (Fig. 5). Laciniae of the maxillae in females presented denticulation patterns separating MP (Santa Cruz), with 2 rows of poorly chitinized lateral teeth, from the remaining groups 
TABLE I

Ia metric properties in females

\begin{tabular}{|c|c|c|c|c|c|c|}
\hline Trait & Group & Obs & Mean & StdDev & Min & Max \\
\hline \multirow[t]{4}{*}{ AIII } & FH & 11 & 194.0 & 14.8 & 175 & 223 \\
\hline & FP & 7 & 172.0 & 14.1 & 160 & 192 \\
\hline & FR & 9 & 153.0 & 4.4 & 147 & 158 \\
\hline & FY & 10 & 181.0 & 9.6 & 168 & 199 \\
\hline \multirow[t]{4}{*}{ EP } & FH & 11 & 199.0 & 14.4 & 181 & 231 \\
\hline & FP & 7 & 170.0 & 4.9 & 162 & 175 \\
\hline & FR & 9 & 195.0 & 11.0 & 184 & 213 \\
\hline & FY & 10 & 206.9 & 8.9 & 196 & 220 \\
\hline \multirow[t]{4}{*}{ AL } & FH & 11 & 366.1 & 46.9 & 290 & 437 \\
\hline & FP & 7 & 327.3 & 26.6 & 285 & 360 \\
\hline & FR & 9 & 338.7 & 48.5 & 258 & 399 \\
\hline & FY & 10 & 372.3 & 20.4 & 330 & 391 \\
\hline \multirow[t]{4}{*}{$\mathrm{BE}$} & FH & 11 & 335.4 & 23.9 & 285 & 375 \\
\hline & FP & 7 & 267.7 & 28.4 & 228 & 300 \\
\hline & FR & 9 & 298.1 & 18.8 & 272 & 330 \\
\hline & FY & 10 & 324.0 & 29.7 & 275 & 370 \\
\hline \multirow[t]{4}{*}{ GA } & FH & 11 & 362.3 & 46.3 & 285 & 442 \\
\hline & FP & 7 & 283.3 & 30.2 & 246 & 329 \\
\hline & FR & 9 & 296.0 & 18.6 & 267 & 328 \\
\hline & FY & 10 & 319.4 & 27.7 & 267 & 360 \\
\hline \multirow[t]{4}{*}{ WL } & FH & 11 & 2006.4 & 106.0 & 1780 & 2130 \\
\hline & FP & 7 & 1721.7 & 54.2 & 1630 & 1790 \\
\hline & FR & 9 & 1772.9 & 71.6 & 1660 & 1840 \\
\hline & FY & 10 & 1985.8 & 67.4 & 1880 & 2070 \\
\hline \multirow[t]{4}{*}{ WW } & $\mathrm{FH}$ & 11 & 459.1 & 42.1 & 410 & 530 \\
\hline & FP & 7 & 438.3 & 16.0 & 420 & 460 \\
\hline & FR & 9 & 424.3 & 20.7 & 380 & 440 \\
\hline & FY & 10 & 453.4 & 23.6 & 410 & 490 \\
\hline \multicolumn{7}{|c|}{ Ib metric properties in males } \\
\hline \multirow[t]{5}{*}{ AIII } & MH & 23 & 224.7 & 14.4 & 194 & 250 \\
\hline & MP & 6 & 188.7 & 8.5 & 182 & 205 \\
\hline & MR & 21 & 193.0 & 9.9 & 177 & 210 \\
\hline & MY & 9 & 197.2 & 16.6 & 170 & 220 \\
\hline & MC & 11 & 196.5 & 10.7 & 171 & 209 \\
\hline \multirow[t]{5}{*}{$\mathrm{EP}$} & MH & 23 & 170.7 & 9.8 & 153 & 187 \\
\hline & MP & 6 & 142.2 & 5.9 & 135 & 150 \\
\hline & MR & 21 & 167.4 & 28.8 & 149 & 288 \\
\hline & MY & 9 & 164.9 & 11.9 & 152 & 185 \\
\hline & $\mathrm{MC}$ & 11 & 161.1 & 5.1 & 153 & 168 \\
\hline \multirow[t]{5}{*}{$\mathrm{AL}$} & MH & 23 & 394.0 & 30.1 & 330 & 450 \\
\hline & MP & 6 & 283.8 & 23.9 & 254 & 320 \\
\hline & MR & 21 & 309.7 & 32.7 & 241 & 380 \\
\hline & MY & 9 & 319.8 & 33.0 & 281 & 368 \\
\hline & $\mathrm{MC}$ & 11 & 323.4 & 30.2 & 266 & 361 \\
\hline \multirow[t]{5}{*}{$\mathrm{BE}$} & MH & 23 & 334.4 & 35.6 & 260 & 407 \\
\hline & MP & 6 & 263.0 & 23.9 & 234 & 289 \\
\hline & MR & 21 & 273.9 & 35.3 & 212 & 347 \\
\hline & MY & 9 & 265.4 & 22.2 & 238 & 302 \\
\hline & $\mathrm{MC}$ & 11 & 291.5 & 29.0 & 250 & 355 \\
\hline \multirow[t]{4}{*}{ GA } & MH & 23 & 359.6 & 40.4 & 278 & 450 \\
\hline & MP & 6 & 288.2 & 16.9 & 263 & 308 \\
\hline & MR & 21 & 314.5 & 28.9 & 273 & 390 \\
\hline & MY & 9 & 328.1 & 15.9 & 310 & 354 \\
\hline
\end{tabular}




\begin{tabular}{llrrrrr}
\hline Trait & Group & Obs & Mean & StdDev & Min & Max \\
\hline \multirow{4}{*}{ WL } & MC & 11 & 333.9 & 28.1 & 302 & 405 \\
& MH & 23 & 2083.4 & 87.5 & 1920 & 220 \\
& MP & 6 & 1640.0 & 72.9 & 1560 & 1740 \\
& MR & 21 & 1745.0 & 84.8 & 1550 & 1890 \\
\multirow{5}{*}{ WW } & MY & 9 & 1744.4 & 110.5 & 1550 & 1930 \\
& MC & 11 & 1856.4 & 73.4 & 1735 & 2000 \\
& MH & 23 & 443.5 & 25.7 & 375 & 480 \\
LL & MP & 6 & 363.3 & 8.2 & 350 & 370 \\
& MR & 21 & 375.0 & 20.5 & 340 & 420 \\
& MY & 9 & 375.0 & 23.9 & 340 & 410 \\
Setae & MC & 11 & 388.3 & 22.1 & 350 & 420 \\
& MH & 23 & 287.2 & 13.8 & 267 & 314 \\
& MP & 6 & 233.5 & 12.8 & 218 & 254 \\
& MR & 21 & 238.2 & 11.8 & 217 & 266 \\
& MY & 9 & 235.0 & 11.2 & 219 & 259 \\
& MC & 11 & 247.6 & 7.5 & 229 & 267 \\
& MH & 10 & 146.5 & 11.7 & 137 & 161 \\
& MP & 10 & 157.7 & 14.1 & 137 & 177 \\
\hline
\end{tabular}

For each variable (trait), measurements are reported in microns. Mean, average value. StdDev: standard deviation; Min: minimum; Max: maximum; Obs: number of specimens measured, except for setae where Obs is the number of setae examined. Measurement of length of setae is also reported in Table III. Females and males are separated into Table Ia and Table Ib, respectively.
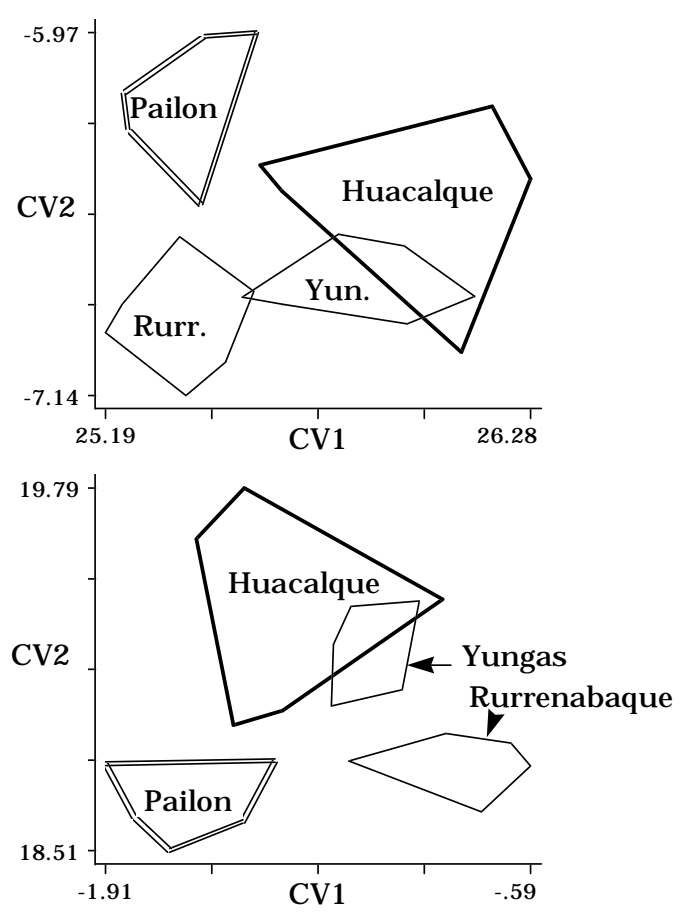

Fig. 3: polygons enclosing specimens of each region after size-in (top) or size-free (bottom) canonical variate analyses (CVA), in females. CV1 and CV2, first and second canonical factors; between brackets, their percent contribution to total variation.
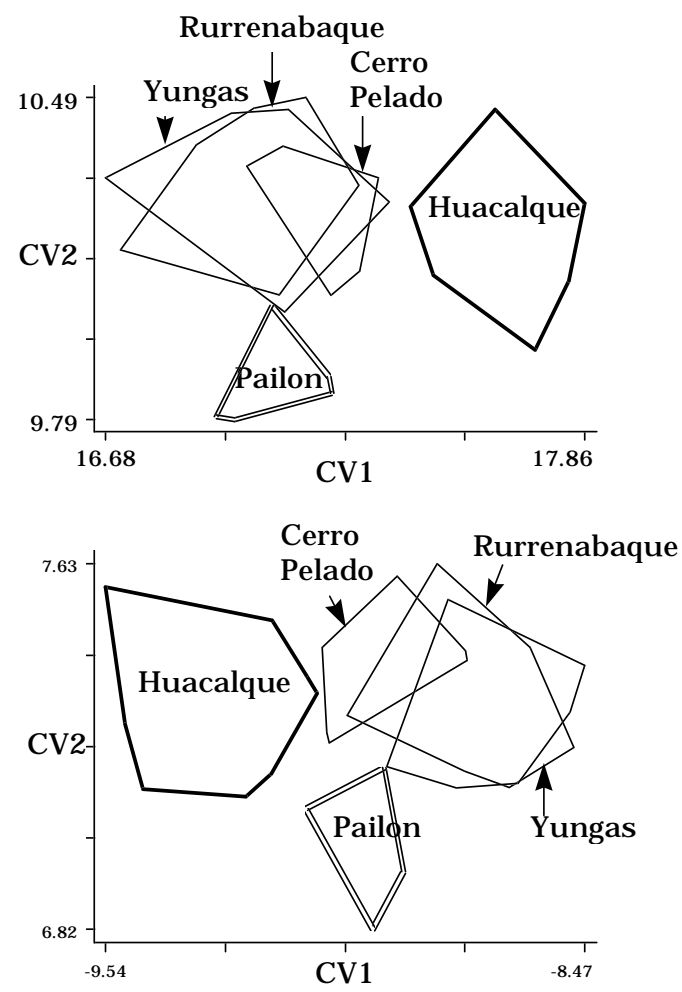

Fig. 4: polygons enclosing specimens of each region after size-in (top) or size-free (bottom) canonical variate analyses (CVA), in males. CV1 and CV2, first and second canonical factors; between brackets, their percent contribution to total variation. 
TABLE II

Reclassification of groups after canonical variate analyses

\begin{tabular}{|c|c|c|c|c|c|}
\hline Analyses & $\mathrm{Pw}$ & $\begin{array}{c}\text { Observed } \\
\text { agreement }\end{array}$ & $\begin{array}{c}\text { Expected } \\
\text { agreement }\end{array}$ & Kappa & $\operatorname{Pr}>\mathrm{Z}$ \\
\hline \multicolumn{6}{|l|}{ Males, SICVA } \\
\hline MH, MY, MR, MC, MP & $<0.001$ & $78 \%$ & $23 \%$ & 0.72 & $<0.000$ \\
\hline $\mathrm{MH},[\mathrm{MY}, \mathrm{MR}, \mathrm{MC}], \mathrm{MP}$ & $<0.001$ & $94 \%$ & $43 \%$ & 0.90 & $<0.000$ \\
\hline \multicolumn{6}{|l|}{ Females, SICVA } \\
\hline MH, MY, MR, MP & $<0.002$ & $77 \%$ & $36 \%$ & 0.65 & $<0.000$ \\
\hline $\mathrm{MH},[\mathrm{MY}, \mathrm{MR}], \mathrm{MP}$ & $<0.001$ & $90 \%$ & $25 \%$ & 0.87 & $<0.000$ \\
\hline \multicolumn{6}{|l|}{ Males, SFCVA } \\
\hline MH, MY, MR, MC, MP & $<0.001$ & $77 \%$ & $22 \%$ & 0.70 & $<0.000$ \\
\hline MH, (MY, MR, MC), MP & $<0.001$ & $93 \%$ & $43 \%$ & 0.87 & $<0.000$ \\
\hline \multicolumn{6}{|l|}{ Females, SFCVA } \\
\hline MH, MY, MR, MP & $<0.001$ & $84 \%$ & $25 \%$ & 0.78 & $<0.000$ \\
\hline MH, (MY, MR), MP & $<0.001$ & $84 \%$ & $36 \%$ & 0.75 & $<0.000$ \\
\hline
\end{tabular}

Pw: refers to significance of the Wilks statistics for each canonical variate analysis, size-in (SICVA) and size-free (SFCVA), on males and females. The analyses on males were performed according to geographic origin (5 groups: MH, MY, MR, MC, MP) or to number of setae on coxites (3 groups: MH, [MY, MR, MC], MP). Accordingly, the analyses on females followed a similar subdivision: 4 groups (FH, FY, FR, FP) and 3 groups (FH, [FY, FR], FP); Observed agreement: indicates the proportion of individuals that have been correctly attributed to their respective group by the model; expected agreement: indicates the proportion of individuals that could have been correctly classified by chance only; the Kappa statistics measure the agreement between observed and expected with level of significance P>z. H: Huacalque, Tarija (1 seta on coxite in males); P: Païlon, Santa Cruz (11-13 setae on coxite); Y: Pararani, Yungas (5-6 setae); C: Cerro Pelado, Alto Beni (5-6 setae); R: Rurrenabaque, Beni (5-6 setae); and between brackets: (MY, MR, MC) or (FY, FR), these populations amalgamated into one group for males (M) or females (F).
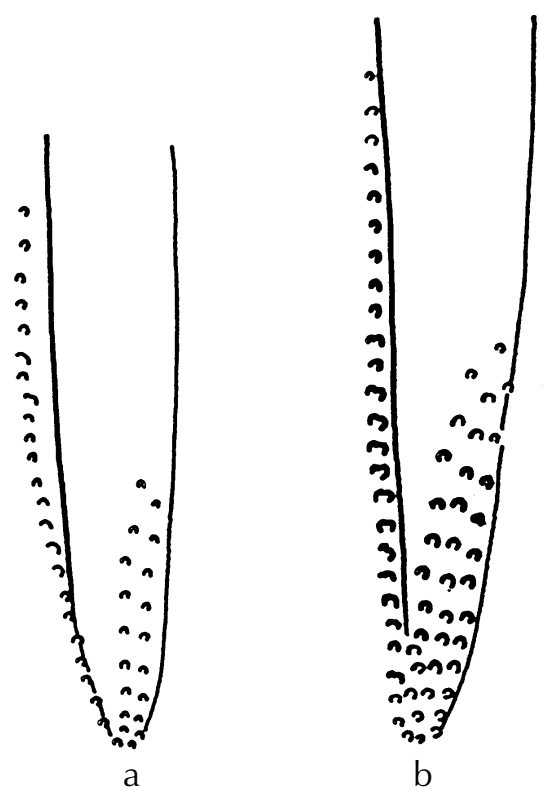

Fig. 5: rows of denticles observed on lateral side of maxillae (laciniae). a, laciniae with two rows of denticles, as observed in the Pailon specimens (FP) coming from Eastern lowlands of Bolivia; $b$, laciniae with $2-4$ rows of more chitinized and numerous denticles, as observed in Lutzomyia quinquefer from the Departments of La Paz (FY, FR) and Tarija $(\mathrm{FH})$. which presented 2-4 rows of more chitinized and more numerous lateral teeth (Fig. 5). In males, the shape of setae also presented differences separating $\mathrm{MH}$ (Huacalque), with one straight, sword-like seta, from the remaining groups showing semi-foliaceous, more bent setae. There was no apparent relation between the general size of male specimens, estimated by PC1, and either the length or shape of setae (Table III).

\section{DISCUSSION}

The male of $L$. quinquefer was represented by Young and Duncan (1994) with 5 setae on the coxite, while Dyar (1929) mentioned 12 setae, a character which was verified by Fairchild and Hertig (1957) on the holotype (Missiones, Argentina). According to this number of coxite setae in Païlon, and to the geographic location of Païlon, this latter sample seems most related to the original description of Dyar (1929). We suppose that Young and Duncan (1994) used for illustration the Bolivian specimens of their collection (Rurrenabaque, Beni), and considered that this character could show individual variation. However, the present study provided no argument to consider the number of setae on coxite as merely individual variation. It was stable within groups, and did not vary significantly in relation with either altitude, temperature or ecology. 
TABLE III

Morphologic and metric features distinguishing male or female Lutzomyia quinquefer collected from four departments of Bolivia: La Paz, Santa Cruz (S. Cruz) and Tarija

\begin{tabular}{|c|c|c|c|c|c|}
\hline Departments & \multicolumn{3}{|c|}{ La Paz and Beni } & Tarija & S. Cruz \\
\hline Altitude & \multicolumn{3}{|c|}{ From $450(\mathrm{R})$ to $1560(\mathrm{Y})$} & 1100 & 200 \\
\hline Males & MY & $\mathrm{MC}$ & MR & $\mathrm{MH}$ & MP \\
\hline $\mathrm{N}$ & 9 & 11 & 21 & 23 & 6 \\
\hline Number of setae & $5-6$ & $5-6$ & $5-6$ & 1 & $11-13$ \\
\hline Length of setae & 155 & 148 & 145 & 146 & 158 \\
\hline Shape of setae & sword & sword & sword & folia & sword \\
\hline Global size & 3 & 4 & 2 & 5 & 1 \\
\hline Females & FY & & FR & $\mathrm{FH}$ & FP \\
\hline $\mathrm{N}$ & 10 & & 9 & 11 & 7 \\
\hline Teeth & $3-4$ & & $3-4$ & $2-3$ & 2 \\
\hline Chitinization & strong & & strong & weak & weak \\
\hline Global size & 3 & & 2 & 4 & 1 \\
\hline
\end{tabular}

Number of setae: counting of setae on coxite in all males of each group; length of setae: average value of the length of setae (see Table I for details); Shape of setae: "sword" refers to the sword-like aspect of setae in most group; in the department of Tarija (MH), the unique seta present on coxite has a different, semi-foliaceous shape ("folia."); global size: ranking of increasing relative sizes (from 1 to 5 in males, 1 to 4 in females) as derived from the values on PC1 (see Fig. 1); teeth: number of rows of lateral teeth on laciniae (maxillae); chitinization: chitinization of teeth appreciated as "strong" or "weak" after visual examination. Altitudes in meters a.s.l. N: number of specimens in each group; F: females; H: Huacalque, Tarija (1 seta on coxite of males); P: Païlon, Santa Cruz (11-13 setae); Y: Pararani (Yungas); C: Cerro Pelado (Alto Beni); and R: Rurrenabaque (Beni), the males of these three latter localities with 5-6 setae on coxite.

Sample sizes were small and unequal among groups, especially in females, but few metric characters were used (4 in females to 5 in males), the results were similar in both sexes, and parallels between quantitative and qualitative characters strengthened the conclusions. In males, the metric differences (continuous characters) were associated with meristic characters (number of setae on the coxite) and with other, qualitative attributes, such as the shape of coxite setae. In females, they were associated with different denticulation patterns and chitinization of the maxilla laciniae.

Four arguments led us to consider these differences as likely to reflect genetic divergence, rather than environmentally induced variation.

First, significant and diagnostic multivariate metric differences persisted even after removing size variation (Table II, Figs 3, 4). Our study compared groups of various geographic locations where ecological, climatic or altitudinal differences are apparent. Removal of size as a differentiation criterion was intended to reveal patterns of variation that would be less influenced by environmental factors (Claridge \& Gillham 1992), and hence more related to evolutionary differences (Hutcheson et al. 1995). Paralleling this observation of size-free differences, there was no apparent association among the number of setae on coxite in males, their length and the general size of the insects (Table III).
Second, the metric variation as described here was related to the number of coxite setae rather than to altitude. Male specimens MR, MC and MY, though from different altitudes (450 to $1560 \mathrm{~m}$ ) showing climatic differences (Lowlands, Subandean Area and Cordillera, see Fig. 1) had the same number of coxite setae (Table III), the same general size (Fig. 2 , bottom), and no significant shape differences (Fig. 3). However, size variation of females in the Department of Beni and La Paz (FR, FY) seemed to follow a pattern more in agreement with an environmental effect on size due to altitude, i.e. larger size at higher altitudes, actually at lower temperatures, elsewhere described as the Bergmann's rule (Ray 1960, Lane 1988).

Third, there was a significant correlation between size or form differences and geographic distances (tested for males only). This relation suggests that the amount of morphological divergence could be predicted by the level of geographic isolation, with no need to infer climatic or ecological differences. This would be in agreement with genetic drift as the main mechanism of differentiation, as it was likely to occur during the Andes orogeny, a major vicariance event for many organisms (Remsen 1984). L. quinquefer from Païlon (P) represents a lowland occidental population of $L$. quinquefer Dyar, while samples with 5-6 (R, C, P) or 1 seta $(\mathrm{H})$ are subandean populations which are 
part of two different geographic basins: the Amazonian basin (R, C, P) of the Rio Beni, and the La Plata basin $(\mathrm{H})$ of the Rio Bermejo.

Fourth, no significant positive correlation could be detected between altitude and general size of the insects (Fig. 2): such a correlation is expected to occur among local populations of the same species. Some evident discrepancies, such as the high altitude of specimens among the smallest ones (MY), could be indicative of genetic differences rather than environmental ones (Marcondes et al. 1998).

Thus, part of the morphological variation disclosed among geographic populations of $L$. quinquefer is interpreted as reflecting evolutionary divergence. Three groups were separated which were congruent with male qualitative attributes (number of coxite setae): (i) Païlon (identified here as L. quinquefer Dyar), (ii) Huacalque and (iii) a third group composed of Rurrénabaque, Cerro Pelado and Parani. These groups showed metric differences unexplained by simple size variation. To which extent they represent true species would require more studies: rather than describing new taxa, we tried to partition the genetic and environmental components of geographical variation (Mayr 1969). This makes sense as long as geographic variation is thought to play a role in species emergence of sand flies (Lane \& Marshall 1981).

\section{ACKNOWLEDGMENTS}

To Dr E Vargas (Director of the Instituto Boliviano de Biologia de Altura) for helping this investigation.

\section{REFERENCES}

Bookstein FL 1989. "Size and shape": a comment on semantics. Syst Zool 38: 173-180.

Burnaby TP 1966 . Growth-invariant discriminant functions and generalized distances. Biometrics 22: 96110.

Claridge MF, Gillham MC 1992. Variation in populations of leafhoppers and planthoppers (Auchenorrhyncha): biotypes and biological species, p. 241259. In RG Foottit \& JT Sorensen (eds), Ordination in the Study of Morphology, Evolution and Systematics of Insects: Applications and Quantitative Genetic Rationales, Elsevier, New York.

Computing Resource Center 1992. Stata Reference Manual. Release 3 (5th edition), Computing Resource Center, Santa Monica, CA.

Dos Reis SF, Pessoa LM, Strauss RE 1990. Application of size-free canonical discriminant analysis to studies of geographic differentiation. Brazil J Genet 13: 509-520.

Dyar HG 1929. The present knowledge of the American species of Phlebotomus Rondani (Diptera, Psychod- idae). Amer J Hyg 10: 112-124.

Fairchild GB, Hertig M 1957 Notes on the Phlebotomus of Panama (Diptera, Psychodidae). XIII. The vexator group with description of new species from Panama and California. Ann Ent Soc Amer 50: 325-334.

Hutcheson HJ, Oliver JH, Houck MA, Strauss RE 1995. Multivariate morphometric discrimination of nymphal and adult forms of the blacklegged tick (Acari: Ixodidae), a principal vector of the agent of Lyme disease in eastern North America. J Med Entomol 32: 827-842.

Landis JR, Koch GG 1977. The measurement of observer agreement for categorical data. Biometrics 33: 159-174.

Lane RP, Marshall J 1981. Geographical variation, races and subspecies, p. 9-19. In PL Forey, The Evolving Biosphere, British Museum (Natural History), London.

Lane RP 1988. Geographic variation in Old World phlebotomine sandflies, p. 77-90. In MW Service, Biosystematics of Haematophagous Insects, Clarendon Press, Oxford.

Mahalanobis PC 1936. On the generalized distance in statistics. Proc Natl Inst Sci India 2: 49-55.

Marcondes CB, Lozovei AL, Galati EAB, Taniguchi HH 1998. The usefulness of Bergmann's rule for the distinction of members of Lutzomyia intermedia species complex (Diptera, Psychodidae, Phlebotominae). Mem Inst Oswaldo Cruz 93: 363-364.

Martins AV, Williams P, Falcão AL 1978. American sandflies. Acad Bras Cienc 1: 1-195.

Mayr E 1969. Principles of Systematic Zoology, McGrawHill, New York, 428 pp.

Pimentel RA 1992. An introduction to ordination, principal components analysis and discriminant analysis, p. 11-28. In RG Foottit \& JT Sorensen (eds), Ordination in the Study of Morphology, Evolution and Systematics of Insects: Applications and Quantitative Genetic Rationales, Elsevier, New York.

Ray C 1960. The application of Bergmann's and Allen's rules to the poikilotherms. J Morphol 106: 85-108.

Remsen Jr JV 1984. High incidence of "Leapfrog" pattern of geographic variation in Andean birds: implications for the speciation process. Science 224: 171173.

Sokal RR, Rohlf JF 1995. Biometry: the Principles and Practice of Statistics in Biological Research, Third edition, WH Freeman and Company, New York, 887 pp.

SAS Institute 1995. JMP® Statistics and Graphics Guide. Version 3.1. SAS Inc., Cary NC.

Wilks SS 1932. Certain generalizations in the analysis of variance. Biometrika 24: 471.

Young DG, Duncan MA 1994. Guide to the Identification and Geographic Distribution of Lutzomyia Sand Flies in Mexico, the West Indies, Central and South America (Diptera: Psychodidae). Mem Amer Inst Entomol 54, Associate Publishers, Gainesville, 881 pp. 